TITLE:

\title{
Hospitalization of mild cases of community-acquired pneumonia decreased more than severe ones during the COVID-19 epidemic
}

\section{$\operatorname{AUTHOR}(\mathrm{S}):$}

Nagano, Hiroyuki; Takada, Daisuke; Shin, Jung-ho; Morishita, Tetsuji; Kunisawa, Susumu; Imanaka, Yuichi

\section{CITATION:}

Nagano, Hiroyuki ...[et al]. Hospitalization of mild cases of community-acquired pneumonia decreased more than severe ones during the COVID-19 epidemic. International Journal of Infectious Diseases 2021, 106: 323-328

\section{ISSUE DATE:}

2021-05

URL:

http://hdl.handle.net/2433/262769

\section{RIGHT:}

(c) 2021 The Authors. Published by Elsevier Ltd on behalf of International Society for Infectious Diseases.; This is an open access article under the Creative Commons Attribution-NonCommercial-NoDerivatives 4.0 International Public License. 


\title{
Hospitalization of mild cases of community-acquired pneumonia decreased more than severe cases during the COVID-19 pandemic
}

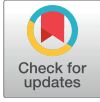

\author{
Hiroyuki Nagano, Daisuke Takada, Jung-ho Shin, Tetsuji Morishita, Susumu Kunisawa, \\ Yuichi Imanaka*
}

Department of Healthcare Economics and Quality Management, Graduate School of Medicine, Kyoto University, Kyoto City, Japan

\section{A R T I C L E I N F O}

\section{Article history:}

Received 15 February 2021

Received in revised form 22 March 2021

Accepted 24 March 2021

\section{Keywords:}

COVID-19

Community-acquired pneumonia

Interrupted time series analysis

\begin{abstract}
A B S T R A C T
Objective: The coronavirus disease 2019 (COVID-19) pandemic has affected all healthcare systems. This study aimed to assess the impact of the COVID-19 pandemic on the number and severity of cases of community-acquired pneumonia (CAP) in Japan.

Methods: Using claims data from the Quality Indicator/Improvement Project (QIP) database, urgent cases of inpatients for CAP from 01 August 2018 to 30 July 2020 were included. The monthly ratios of inpatient cases were compared from August 2018 to July 2019 and August 2019 to July 2020 as a year-over-year comparison. These ratios were also compared according to the "A-DROP" severity score, and an interrupted time series (ITS) analysis was performed to evaluate the impact of the COVID-19 pandemic on the monthly number of inpatient cases.

Results: This study included a total of 67,900 inpatient cases for CAP in 262 hospitals. During the COVID-19 pandemic (defined as the period between March and July 2020) the number of inpatient cases for CAP drastically decreased compared with the same period in the previous year $(-48.1 \%)$, despite a temporary reduction in the number of other urgent admissions. The number of inpatient cases decreased according to the severity of pneumonia. Milder cases showed a greater decrease in the year-over-year ratio than severe ones: mild $-55.2 \%$, moderate $-45.8 \%$, severe $-39.4 \%$, and extremely severe $-33.2 \%$. The ITS analysis showed that the COVID-19 pandemic significantly reduced the monthly number of inpatient cases for CAP (estimated decrease: -1233 cases; $95 \%$ CI -521 to -1955 ).

Conclusions: This study showed a significant reduction in the number of inpatient cases for CAP during the COVID-19 pandemic in Japan. The milder cases showed a greater decrease in the year-over-year ratio of the number of inpatient cases.

(C) 2021 The Authors. Published by Elsevier Ltd on behalf of International Society for Infectious Diseases. This is an open access article under the CC BY-NC-ND license (http://creativecommons.org/licenses/by-nc-
\end{abstract}

\section{Introduction}

Coronavirus disease 2019 (COVID-19) was first recognized in early December 2019 in Wuhan, China, and spread globally in 2020 (Zhu et al., 2020). In Japan, the government focused on controlling the clusters of infected cases by preventing the spread in closed spaces, crowded areas, and close-contact settings (Shimizu et al., 2020). However, the daily number of new COVID-19 infections increased in March 2020. The Japanese government then declared a state of emergency and requested self-quarantine and social distancing in seven prefectures on April 7 and 47 prefectures on

\footnotetext{
* Corresponding author at: Department of Healthcare Economics and Quality Management, Graduate School of Medicine, Kyoto University, Yoshida Konoe-cho, Sakyo-ku, Kyoto 606-8501, Japan.

E-mail address: imanaka-y@umin.net (Y. Imanaka).
}

April 16 (Prime Minister of Japan and His Cabinet, 2020). Consequently, the COVID-19 pandemic has changed the lifestyle of many Japanese people, as individual hygiene, maintenance of social distance and suspension of large-scale gatherings have been strongly encouraged.

Community-acquired pneumonia (CAP) is defined as a lower respiratory tract infection that is acquired outside the hospital setting (Metlay et al., 2019). CAP is one of the most common infectious disease responsible for hospital admission and mortality, especially in the elderly. A decrease in inpatient and outpatient cases with CAP has been reported during the COVID-19 pandemic (Wu et al., 2020; Yamamoto et al., 2020). However, few studies have focused on finding the type of CAP patients who were impacted by the COVID-19 pandemic. Therefore, this retrospective cohort study was performed using a large-scale Japanese database. The study sought to evaluate the impact of the COVID-19 pandemic on the number and severity of inpatients with CAP in Japan. 


\section{Methods}

\section{Data source}

For this retrospective cohort study, Diagnosis Procedure Combination (DPC) data were extracted from the Quality Indicator/Improvement Project (QIP) database. The QIP is administered by the Department of Healthcare Economics and Quality Management in Kyoto University (Hamada et al., 2012), which regularly collects DPC data from acute-care hospitals in Japan that voluntarily participate in the project. These hospitals include both public and private facilities of various sizes. In 2019, the number of general beds at the participating hospitals ranged from 30 to 1151 (excluding psychiatric, infectious diseases, and tuberculosis beds, according to the Japanese classification of hospital beds). The DPC/ per-diem payment system (PDPS) is a Japanese prospective payment system applied to acute-care hospitals. In 2018, a total of 1730 hospitals used the DPC/PDPS, accounting for $54 \%$ (482,618 of 891,872 ) of all the general hospital beds in Japanese hospitals (Ministry of Health, Labour and Welfare, 2018a; Ministry of Health, Labour and Welfare, 2018b). The DPC consists of several data files, including forms 1,3 , and 4 and files $\mathrm{D}, \mathrm{E}, \mathrm{F}, \mathrm{H}$, and $\mathrm{K}$ (Ministry of Health, Labour and Welfare, 2020). This study used form 1, file E, and file F. Form 1 contains discharge summaries, which include the International Classification of Diseases 10th Revision (ICD-10) codes classifying the main diagnosis, trigger diagnosis, most and second-most medical-resource-intensive diagnoses, up to 10 comorbidities, and 10 complications during hospitalization. Form 1 also includes the following patient details: age, sex, body mass index (BMI), components of the Barthel index (independence of feeding, bathing, grooming, dressing, bowels, bladder, toilet use, transfers from bed to chair, mobility on level surfaces, and stairs), medical procedures, the pneumonia severity score according to the A-DROP scoring system (a modified version of the CURB-65 scoring in Japan) at the onset, and the type of pneumonia (communityacquired pneumonia, nosocomial pneumonia, or diagnosis other than pneumonia). Files $\mathrm{E}$ and $\mathrm{F}$ contain information on all medical services, medications, and equipment for both inpatients and outpatients. Files $\mathrm{E}$ and $\mathrm{F}$ include the name of the diagnosis, the start date of diagnosis, and the date of visit for outpatients.

\section{Study population}

This study included cases of patients aged $\geq 18$ years and who were urgently hospitalized for pneumonia between 01 August 2018 and 31 July 2020. Urgent admission was defined as unplanned hospital admission and pneumonia, as stipulated in the ICD-10 codes in the 2013 version: J10.0, J11.0, J12.X, J13, J14, J15.X-J18.x, A48.1, B01.2, B05.2, B37.1, and B59. The exact contents of the ICD-10 codes are specified in Table S1 in the Supplemental material. CAP was identified using the corresponding variable in the DPC data. Inpatient cases with ICD-10 codes were included in the following data fields: main diagnosis, trigger diagnosis, and most medical resource-intensive diagnosis. COVID-19 was not included in the study population. The urgent admissions for diagnosis other than pneumonia (other urgent admissions) were extracted for comparison. The outpatient CAP cases newly diagnosed with pneumonia were also extracted from files $\mathrm{E}$ and $\mathrm{F}$ in the same period to evaluate the trend of overall patients with CAP. New diagnosis of pneumonia was defined as the coincidence between the start date of diagnosis and the date of visit.

\section{Year-over-year comparison}

The primary outcome of interest was the change in the monthly number of inpatient CAP cases during the COVID-19 pandemic (defined as between March and July 2020). The monthly ratio of inpatient cases between August 2018 to July 2019 and August 2019 to July 2020 was retrospectively compared as a year-over-year comparison. The year-over-year comparisons were also performed for other urgent admissions and outpatient pneumonia cases. The year-over-year comparison of the inpatient cases in each group of the A-DROP scoring system from March to July in 2019 and 2020 were also compared. The A-DROP system is a 6-point scale (0-5) that assess the clinical severity of CAP according to the following parameters: (i) age (male $\geq 70$ years, female $\geq 75$ years); (ii) dehydration (blood urea nitrogen (BUN) $\geq 210 \mathrm{mg} / \mathrm{L}$ ); (iii) respiratory failure (arterial oxygen saturation $(\mathrm{SpO} 2) \leq 90 \%$ or partial pressure of oxygen in arterial blood ( $\mathrm{PaO} 2) \leq 60 \mathrm{mmHg}$ ); (iv) orientation disturbance (confusion); and (v) low blood pressure (systolic blood pressure (SBP) $\leq 90 \mathrm{mmHg}$ ) (Shindo et al., 2008). The A-DROP score was divided into four severity classes: mild, 0 ; moderate, $1-2$; severe, 3 ; and extremely severe, 45 . Specifically, the locally estimated scatterplot smoothing (LOESS) was used to visualize smooth trend curves.

\section{Descriptive analysis}

The characteristics of inpatient cases from March to July 2019 and 2020 were compared. The characteristics were described for the overall cases and each group of the A-DROP scoring system. Body mass index, the Carlson Comorbidity index, and the Barthel index variables were presented because they were associated with the mortality of inpatient pneumonia cases (Nguyen et al., 2019; Murcia et al., 2010; Takada et al., 2020). Age and hospital length of stay were expressed as median values (interquartile range). These variables between the two groups were compared using MannWhitney U tests. The categorical data (such as sex) were compared using Chi-square or Fisher's exact tests. All statistical analyses were performed with $\mathrm{R}$ version 3.6.0 ( $\mathrm{R}$ Foundation for Statistical Computing, Vienna, Austria).

\section{Interrupted time series analyses for changes in case numbers}

An interrupted time series (ITS) analysis was performed to evaluate the impact of the COVID-19 pandemic on the monthly number of inpatient cases (Bernal et al., 2017). The changes in the number of monthly cases were statistically tested after adjusting for seasonality using a Fourier term. It was hypothesized that the COVID-19 pandemic would reduce the monthly number of cases after March 2020, since this was when the first wave of COVID-19 started (Shimizu et al., 2020). A sensitivity analysis was also conducted; to assess the sensitivity of the findings to a change in time point, this parameter was changed. The candidate intervention time points were as follows: (1) February 2020, the Ministry of Health, Labour and Welfare of Japan requested pharmacies and supermarkets in Japan to impose restrictions on purchases due to shortages of face masks and disinfectants (Sakamoto et al., 2020); and (2) April 2020, the Government of Japan declared a state of emergency (Prime Minister of Japan and His Cabinet, 2020). An interrupted time series (ITS) analysis was also performed to evaluate the impact of the COVID-19 pandemic on the monthly number of outpatient cases.

\section{Results}

This study included a total of 67,900 inpatient CAP cases in 262 hospitals. It also extracted 1,425,133 other urgent admissions and 48,288 outpatient CAP cases. The monthly numbers of cases and year-over-year ratios are displayed in Table S2 in the Supplemental material. During the COVID-19 pandemic, the number of cases decreased compared with the same period the year before 
(inpatient CAP cases $-48.1 \%$, other urgent admissions $-9.1 \%$, and outpatient CAP cases -26.7\%). The year-over-year ratios of inpatient CAP cases and other urgent admissions are illustrated in Figure 1. The number of inpatient CAP cases drastically decreased during the COVID-19 pandemic, despite a temporary reduction in the number of other urgent admissions.

Figure 2 shows the year-over-year ratios of the inpatient cases in each group of the A-DROP scoring system. The monthly numbers of cases and year-over-year ratios in each group of the A-DROP scoring system are displayed in Table S3 in the Supplemental material. The year-over-year ratios for the milder inpatient cases decreased more than for the severe cases during the COVID-19 pandemic: mild $-55.2 \%$, moderate $-45.8 \%$, severe $-39.4 \%$, extremely severe $-33.2 \%$. Table 1 displays the baseline characteristics of the inpatient cases in each group. The ratio of inpatient cases with chronic pulmonary disease in the mild group was particularly lower than during the same period in 2019 (21.5\% vs 17.5\%). For overall cases, the in-hospital mortality was more elevated during the COVID-19 pandemic than the same period in 2019 (6.4\% vs $9.3 \%)$. The ratios of several categories associated with pneumonia mortality, such as the Charlson Comorbidity index $\geq 1$ (71.6\%$73.8 \%)$, the Charlson Comorbidity index $\geq 2(40.8 \%-43.9 \%)$, the Barthel index $\leq 80$ (50.7\%-54.2\%), and BMI $<17 \mathrm{~kg} / \mathrm{m}^{2}(14.1 \%-$ $16.7 \%)$ were also increased. In each group, the ratios of in-hospital death and these categories were also increased.

The ITS analysis showed a significant reduction in the monthly number of inpatient CAP cases (estimated decrease: -1233 cases; 95\% CI -521 to -1955 ) and outpatient CAP cases (estimated decrease: -1808 cases; $95 \% \mathrm{CI}-656$ to -2960 ). These findings were largely unaffected by the change of the time point, as shown in Table S4 in the Supplemental material.

\section{Discussion}

This study used a large-scale administrative database to analyze the impact of the COVID-19 pandemic on the number and severity of inpatient CAP cases. The main findings were as follows: (1) a significant reduction in the number of inpatient CAP cases, despite a temporary reduction in the number of other urgent admissions during the COVID-19 pandemic; (2) a greater decrease in the yearover-year ratio in milder cases; (3) a significant decrease in the number of inpatient cases and outpatient CAP cases.

The decrease in inpatient CAP cases was consistent with previous reports (Wu et al., 2020; Yamamoto et al., 2020). This study revealed that milder cases of pneumonia were associated with a greater decrease in the year-over-year ratio of the number of inpatient cases. Many patients were reluctant to seek medical evaluation for fear of exposure to COVID-19 in other hospital departments, including pediatrics and cardiology (Hammad et al., 2021; Lazzerini et al., 2020). The Japanese government urged patients with mild symptoms to stay at home from 22 February 2020 (Sakamoto et al., 2020). Therefore, the patients with mild

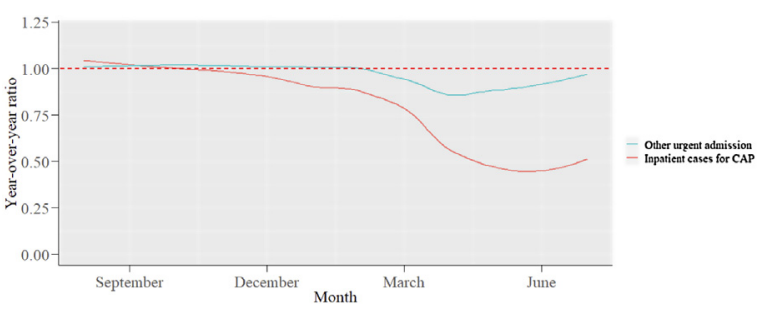

Figure 1. Year-over-year ratio of the number of other urgent admission for diagnosis other than pneumonia and inpatient cases for CAP.

Other urgent admission: urgent admission for diagnosis other than pneumonia. CAP: community-acquired pneumonia.

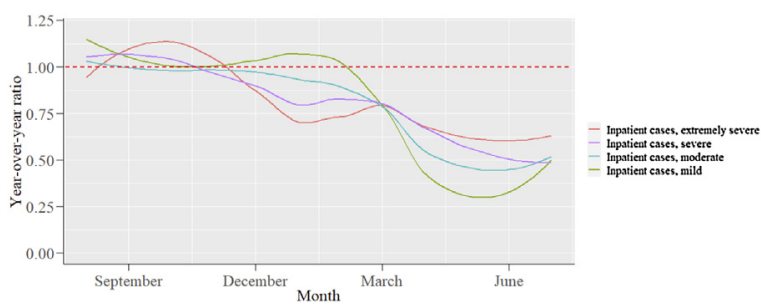

Figure 2. Year-over-year ratio of the number of inpatient cases for communityacquired pneumonia in each group of the A-DROP scoring system.

symptoms might have the same tendency to avoid medical visits in this study population.

There are still two reasons for the decrease in inpatient CAP cases. First, the change in lifestyle itself might have reduced the onset of pneumonia. This study included inpatient cases in the elderly with a median age of 80 years. The main pathogens responsible for pneumonia in the elderly include Streptococcus pneumonia, Haemophilus influenzae, and Enterobacteriaceae (Janssens, 2005). Aspiration of microorganisms inside the oral cavity is also a major cause of pneumonia in the elderly because the elderly have risk factors such as impaired swallowing and cough reflex (Mandell and Niederman, 2019). These bacteria do not directly spread from human to human.

The COVID-19 pandemic has changed lifestyles by encouraging individual-level hygiene (wearing a mask outside, keeping social distance, disinfecting with alcohol, and washing hands frequently) and community-level prevention measures (promotion of remote work, suspension of mass gathering) (Abe et al., 2021). Limiting family visits was instigated in many aged-care facilities in Japan (ABC News, 2020). These lifestyle changes might have prevented much person-to-person disease transmission, such as respiratory viral diseases (de Souza Luna et al., 2020; Jones, 2020) and tuberculosis (Komiya et al., 2020). In Japan, influenza activity was lower in the 2019/2020 season compared with the 2014-2019 seasons (Sakamoto et al., 2020). As for children, there was a mild decrease in inpatient influenza cases after school closures for the COVID-19 pandemic in Japan (Kishimoto et al., 2021). Therefore, the decrease in pneumonia caused by viruses, including the influenza virus, could be one cause for the decrease in inpatient CAP cases.

A respiratory viral infection is also related to the onset of bacterial pneumonia. A respiratory viral infection is an important risk factor for bacterial pneumonia because respiratory viruses affect the host's pulmonary defense and impair bacterial clearance (Prasso and Deng, 2017). A previous report showed a significant increase in hospitalizations due to pneumococcal pneumonia during the 2009 influenza pandemic (Weinberger et al., 2012). The behavioral change due to COVID-19 infection control may have prevented viral respiratory infections and consequently bacterial pneumonia. Therefore, it might have contributed to the decrease in the onset of pneumonia during the COVID-19 pandemic.

This study also showed that the ratio of inpatient cases with milder chronic pulmonary disease decreased during the COVID-19 pandemic compared with the same period in 2019. Previous studies have revealed that the change in patient behavior and physical environment during the COVID-19 pandemic could have contributed to the decrease in hospital admissions for acute exacerbations of chronic obstructive pulmonary diseases and asthma (Abe et al., 2021; Chan et al., 2020). These changes could have also contributed to the decrease in inpatient CAP cases, especially for patients with milder diseases.

Second, a shortage of hospital beds and manpower could have restricted hospitalization (Zhou et al., 2020); however, Table S2 
Table 1

The characteristics of inpatient cases for CAP in each group of the A-DROP scoring system between March and July 2019 and 2020.

\begin{tabular}{|c|c|c|c|c|c|c|c|c|c|c|c|c|c|c|c|}
\hline & \multicolumn{2}{|l|}{ All } & \multirow[b]{2}{*}{$\mathrm{p}$-Value } & \multicolumn{2}{|l|}{ Mild } & \multirow[b]{2}{*}{$\begin{array}{l}\mathrm{p}- \\
\text { Value }\end{array}$} & \multicolumn{2}{|l|}{ Moderate } & \multirow[b]{2}{*}{$\begin{array}{l}\mathrm{p}- \\
\text { Value }\end{array}$} & \multicolumn{2}{|l|}{ Severe } & \multirow[b]{2}{*}{$\begin{array}{l}\text { p- } \\
\text { Value }\end{array}$} & \multicolumn{2}{|c|}{ Extremely severe } & \multirow[b]{2}{*}{$\mathrm{p}$-Value } \\
\hline & 2019 & 2020 & & 2019 & 2020 & & 2019 & 2020 & & 2019 & 2020 & & 2019 & 2020 & \\
\hline Number of cases & 15,540 & 8521 & & 1951 & 874 & & 9981 & 5407 & & 2737 & 1658 & & 871 & 582 & \\
\hline Age, median (IQR) & $\begin{array}{l}81.0[71.0- \\
87.0]\end{array}$ & $\begin{array}{l}81.0[73.0- \\
88.0]\end{array}$ & $<0.001$ & $\begin{array}{l}61.0[46.0- \\
68.0]\end{array}$ & $\begin{array}{l}60.0[47.0- \\
67.0]\end{array}$ & 0.19 & $\begin{array}{l}82.0[75.0- \\
88.0]\end{array}$ & $\begin{array}{l}82.0[75.0- \\
88.0]\end{array}$ & 0.15 & $\begin{array}{l}85.0[79.0- \\
90.0]\end{array}$ & $\begin{array}{l}85.0[79.0- \\
90.0]\end{array}$ & 0.90 & $\begin{array}{l}85.0[80.0- \\
91.0]\end{array}$ & $\begin{array}{l}85.0[80.0- \\
90.0]\end{array}$ & 0.52 \\
\hline Sex (male), n (\%) & 8809 (56.7) & $5408(63.5)$ & $<0.001$ & $881(45.2)$ & $470(53.8)$ & $<0.001$ & $5728(57.4)$ & $3467(64.1)$ & $<0.001$ & $1681(61.4)$ & $1092(65.9)$ & 0.01 & $519(59.6)$ & $379(65.1)$ & 0.04 \\
\hline $\begin{array}{r}\text { Confirmed bacterial } \\
\text { pneumonia, } \mathrm{n}(\%)\end{array}$ & 7789 (50.1) & $4342(51.0)$ & 0.22 & $980(50.2)$ & 454 (51.9) & 0.42 & 4939 (49.5) & $2728(50.5)$ & 0.26 & $1400(51.2)$ & $850(51.3)$ & 0.97 & $470(54.0)$ & $310(53.3)$ & 0.84 \\
\hline \multicolumn{16}{|l|}{ Comorbidities } \\
\hline $\begin{array}{l}\text { Myocardial infarction, } \\
\mathrm{n}(\%)\end{array}$ & $305(2.0)$ & $170(2.0)$ & 0.90 & $12(0.6)$ & $9(1.0)$ & 0.34 & $199(2.0)$ & $113(2.1)$ & 0.73 & $72(2.6)$ & $36(2.2)$ & 0.39 & $22(2.5)$ & $12(2.1)$ & 0.69 \\
\hline $\begin{array}{l}\text { Congestive heart } \\
\text { failure, } \mathrm{n}(\%)\end{array}$ & $3093(19.9)$ & $1905(22.4)$ & $<0.001$ & $78(4.0)$ & $53(6.1)$ & 0.02 & $1931(19.3)$ & $1130(20.9)$ & 0.02 & $827(30.2)$ & $523(31.5)$ & 0.37 & $257(29.5)$ & $199(34.2)$ & 0.07 \\
\hline $\begin{array}{r}\text { Cerebrovascular } \\
\text { disease, } \mathrm{n}(\%)\end{array}$ & 1797 (11.6) & $971(11.4)$ & 0.71 & $69(3.5)$ & $32(3.7)$ & 0.96 & 1187 (11.9) & $614(11.4)$ & 0.34 & $390(14.2)$ & $237(14.3)$ & 1.00 & $151(17.3)$ & $88(15.1)$ & 0.30 \\
\hline Dementia, n (\%) & $2022(13.0)$ & $1129(13.2)$ & 0.62 & $20(1.0)$ & $6(0.7)$ & 0.51 & $1343(13.5)$ & $718(13.3)$ & 0.78 & $464(17.0)$ & $292(17.6)$ & 0.60 & $195(22.4)$ & $113(19.4)$ & 0.20 \\
\hline $\begin{array}{l}\text { Chronic pulmonary } \\
\text { disease, } \mathrm{n}(\%)\end{array}$ & $3545(22.8)$ & 1869 (21.9) & 0.12 & $419(21.5)$ & $153(17.5)$ & 0.02 & $2339(23.4)$ & $1209(22.4)$ & 0.14 & $626(22.9)$ & $402(24.2)$ & 0.31 & $161(18.5)$ & $105(18.0)$ & 0.89 \\
\hline $\begin{array}{l}\text { Diabetes without } \\
\text { chronic } \\
\text { complication, n (\%) }\end{array}$ & $2380(15.3)$ & 1359 (15.9) & 0.20 & $207(10.6)$ & $108(12.4)$ & 0.19 & $1603(16.1)$ & $890(16.5)$ & 0.54 & $439(16.0)$ & $274(16.5)$ & 0.70 & $131(15.0)$ & $87(14.9)$ & 1.00 \\
\hline $\begin{array}{l}\text { Diabetes with chronic } \\
\text { complication, } \mathrm{n}(\%)\end{array}$ & $628(4.0)$ & $352(4.1)$ & 0.76 & $37(1.9)$ & $22(2.5)$ & 0.36 & $432(4.3)$ & $228(4.2)$ & 0.78 & $122(4.5)$ & $82(4.9)$ & 0.50 & $37(4.2)$ & $20(3.4)$ & 0.52 \\
\hline Renal disease, n (\%) & $1169(7.5)$ & $782(9.2)$ & $<0.001$ & $39(2.0)$ & $23(2.6)$ & 0.36 & $754(7.6)$ & $442(8.2)$ & 0.18 & $292(10.7)$ & $246(14.8)$ & $<0.001$ & $84(9.6)$ & $71(12.2)$ & 0.14 \\
\hline $\begin{array}{l}\text { Any malignancy except } \\
\text { skin, } \mathrm{n}(\%)\end{array}$ & 1766 (11.4) & $1146(13.4)$ & $<0.001$ & $171(8.8)$ & $101(11.6)$ & 0.02 & $1179(11.8)$ & $762(14.1)$ & $<0.001$ & 317 (11.6) & $207(12.5)$ & 0.40 & $99(11.4)$ & $76(13.1)$ & 0.37 \\
\hline $\begin{array}{l}\text { Charlson Comorbidity } \\
\text { index } \geqq 1\end{array}$ & $11,119(71.6)$ & $6289(73.8)$ & $<0.001$ & 969 (49.7) & $464(53.1)$ & 0.10 & $7321(73.3)$ & $3983(73.7)$ & 0.69 & $2158(78.8)$ & $1377(83.1)$ & 0.00 & $671(77.0)$ & 465 (79.9) & 0.22 \\
\hline $\begin{array}{l}\text { Charlson Comorbidity } \\
\text { index } \geqq 2\end{array}$ & $6347(40.8)$ & 3741 (43.9) & $<0.001$ & 399 (20.5) & $216(24.7)$ & 0.01 & $4199(42.1)$ & $2362(43.7)$ & 0.06 & $1322(48.3)$ & $881(53.1)$ & 0.00 & $427(49.0)$ & $282(48.5)$ & 0.87 \\
\hline Barthel index & & & $<0.001$ & & & 0.37 & & & 0.00 & & & 0.10 & & & 0.72 \\
\hline$>80$ & $5682(36.6)$ & $2750(32.3)$ & & $1527(78.3)$ & $663(75.9)$ & & $3594(36.0)$ & 1785 (33.0) & & $484(17.7)$ & $256(15.4)$ & & $77(8.8)$ & $46(7.9)$ & \\
\hline$\leq 80$ (dependent) & $7872(50.7)$ & $4620(54.2)$ & & $318(16.3)$ & $158(18.1)$ & & $5094(51.0)$ & $2873(53.1)$ & & $1796(65.6)$ & $1135(68.5)$ & & $664(76.2)$ & $454(78.0)$ & \\
\hline Missing & $1986(12.8)$ & $1151(13.5)$ & & $106(5.4)$ & $53(6.1)$ & & $1293(13.0)$ & 749 (13.9) & & 457 (16.7) & $267(16.1)$ & & $130(14.9)$ & $82(14.1)$ & \\
\hline Body mass index, $\mathrm{n}(\%)$ & & & $<0.001$ & & & $<0.001$ & & & $<0.001$ & & & 0.20 & & & 0.33 \\
\hline$<17 \mathrm{~kg} / \mathrm{m}^{2}$ & $2196(14.1)$ & $1420(16.7)$ & & $165(8.5)$ & $91(10.4)$ & & 1369 (13.7) & $889(16.4)$ & & $462(16.9)$ & $322(19.4)$ & & $200(23.0)$ & $118(20.3)$ & \\
\hline $17-30 \mathrm{~kg} / \mathrm{m}^{2}$ & $11,447(73.7)$ & $5952(69.9)$ & & $1576(80.8)$ & $643(73.6)$ & & $7427(74.4)$ & $3,821(70.7)$ & & $1922(70.2)$ & $1131(68.2)$ & & $522(59.9)$ & $357(61.3)$ & \\
\hline$\geq 30 \mathrm{~kg} / \mathrm{m}^{2}$ & $455(2.9)$ & $216(2.5)$ & & $93(4.8)$ & $56(6.4)$ & & $293(2.9)$ & $124(2.3)$ & & $50(1.8)$ & $28(1.7)$ & & $19(2.2)$ & $8(1.4)$ & \\
\hline Missing & $1442(9.3)$ & $933(10.9)$ & & $117(6.0)$ & $84(9.6)$ & & $892(8.9)$ & $573(10.6)$ & & $303(11.1)$ & $177(10.7)$ & & $130(14.9)$ & $99(17.0)$ & \\
\hline $\begin{array}{l}\text { Mechanical ventilation, } \\
\mathrm{n}(\%)\end{array}$ & $579(3.7)$ & $326(3.8)$ & 0.72 & $17(0.9)$ & $10(1.1)$ & 0.63 & $246(2.5)$ & $140(2.6)$ & 0.68 & $178(6.5)$ & $106(6.4)$ & 0.94 & $138(15.8)$ & $70(12.0)$ & 0.05 \\
\hline $\begin{array}{l}\text { Length of hospital stay, } \\
\text { median days (IQR) }\end{array}$ & $\begin{array}{l}12.0[8.0- \\
19.0]\end{array}$ & $\begin{array}{l}13.00[9.0- \\
22.0]\end{array}$ & $<0.001$ & $\begin{array}{l}8.0[6.0- \\
11.0]\end{array}$ & $\begin{array}{l}9.0[6.0- \\
12.0]\end{array}$ & 0.16 & $\begin{array}{l}12.0[9.0- \\
19.0]\end{array}$ & $\begin{array}{l}13.0[9.0- \\
21.0]\end{array}$ & $<0.001$ & $\begin{array}{l}15.0[10.0- \\
25.0]\end{array}$ & $\begin{array}{l}16.0[10.0- \\
27.0]\end{array}$ & 0.14 & $\begin{array}{l}18.0[10.0- \\
31.0]\end{array}$ & $\begin{array}{l}16.0[9.0- \\
28.0]\end{array}$ & 0.02 \\
\hline In-hospital death, n (\%) & $995(6.4)$ & $794(9.3)$ & $<0.001$ & $10(0.5)$ & $13(1.5)$ & 0.02 & $411(4.1)$ & $338(6.3)$ & $<0.001$ & $337(12.3)$ & $255(15.4)$ & 0.00 & $237(27.2)$ & $188(32.3)$ & 0.04 \\
\hline
\end{tabular}

CAP: community-acquired pneumonia. 
shows that the number of other urgent admissions recovered to about $90 \%$. This result suggests an absence of a large number of restrictions. Additionally, the decline in outpatient CAP cases cannot be explained by the restrictions in hospitalization.

This study revealed that in-hospital mortality was more elevated during the COVID-19 pandemic than the same period in 2019 for overall cases and each group of the A-DROP scoring system. In Table 1 , the proportion of inpatient cases with a higher Charlson Comorbidity index, functional dependence (Barthel index $\leq 80$ points), and $\mathrm{BMI}<17 \mathrm{~kg} / \mathrm{m}^{2}$ increased during the COVID-19 pandemic. These factors were associated with higher mortality in patients with pneumonia (Nguyen et al., 2019; Murcia et al., 2010; Takada et al., 2020). These changes might have contributed to the elevated mortality in each group of the A-DROP scoring system during the COVID-19 pandemic.

This study had several limitations. First, the study population was restricted to patients in hospitals that voluntarily participated in the QIP; therefore, selection bias cannot be excluded. Second, the diagnoses of the outpatient pneumonia cases recorded in files $\mathrm{E}$ and $\mathrm{F}$ were not classified as in form 1 and may not have been sufficiently robust. However, files $\mathrm{E}$ and $\mathrm{F}$ contained the start date of diagnosis and date of visit and allowed the newly diagnosed outpatient cases with pneumonia to be extracted. Therefore, the trend for the number of outpatient pneumonia cases was approximately assessed. Despite these limitations, this research provided important information on the impact of the COVID-19 pandemic on CAP inpatients using a large-scale Japanese database. Further studies are warranted to identify the long-term impact of the decrease in inpatient CAP cases on patient outcomes and healthcare systems.

In conclusion, a marked reduction in inpatient CAP cases was observed during the COVID-19 pandemic in Japan using large-scale administrative data. The decrease in the year-over-year ratio of the number of inpatient cases was greater for the milder pneumonia cases.

\section{Ethical considerations}

This research was conducted according to the Ethical Guidelines for Medical and Health Research Involving Human Subjects of the MHLW, Japan (a provisional translation is avail- able from: https:// www.mhlw.go.jp/file/06-Seisakujouhou-10600000-Daijinkanboukouseikagakuka/0000080278.pdf). In the accordance of the Guidelines, informed consent was not required for research not utilizing human biological specimens, and information utilized in the research was anonymized. The Ethics Committee, Graduate School of Medicine, Kyoto University approved the study (approval number: R0135).

\section{Funding}

This study was supported by JSPS KAKENHI Grant Numbers JP19H01075 from the Japan Society for the Promotion of Science (https://www.jsps.go.jp/english/e-grants/), Health Labour Sciences Research Grants from the Ministry of Health, Labour and Welfare, Japan, Grant Numbers 20HA2003 (https://www.mhlw. go.jp/stf/seisakunitsuite/bunya/hokabunya/kenkyujigyou/index.html), and by GAP Fund Program of Kyoto University,GAP Fund Program Type B (http://www.venture.saci.kyoto-u.ac.jp/? page_id=83\#gp) to Y. I. The funders played no role in the study design, data collection and analysis, decision to publish, or preparation of the manuscript.

\section{Declaration of interests}

The authors declare that they have no known competing financial interests or personal relationships that could have appeared to influence the work reported in this paper.

\section{CRediT authorship contribution statement}

Hiroyuki Nagano: Conceptualization, Methodology, Software, Formal analysis, Writing - original draft, Writing - review \& editing, Visualization. Daisuke Takada: Conceptualization, Methodology, Software, Validation, Investigation, Writing - review \& editing. Jung-ho Shin: Conceptualization, Software, Validation, Investigation, Data curation, Writing - review \& editing. Tetsuji Morishita: Conceptualization, Methodology, Software, Validation, Investigation, Writing - review \& editing. Susumu Kunisawa: Conceptualization, Validation, Investigation, Data curation, Resources, Writing - review \& editing. Yuichi Imanaka: Conceptualization, Validation, Investigation, Resources, Writing - review \& editing, Supervision, Project administration, Funding acquisition.

\section{Acknowledgements}

We thanked the staff of participating hospitals in QIP.

\section{Appendix A. Supplementary data}

Supplementary material related to this article can be found, in the online version, at doi:https://doi.org/10.1016/j.ijid.2021.03.074.

\section{References}

ABC News. Japan's aged care facilities remain locked down amid a COVID-19 third wave, and now there are fears residents may develop dementia. 2020. https:// www.abc.net.au/news/2020-11-29/how-a-third-wave-of-coronavirus-covid19-hit-japan/12915838.

Abe $K$, Miyawaki A, Nakamura $M$, Ninomiya $H$, Kobayashi $Y$. Trends in hospitalizations for asthma during the COVID-19 outbreak in Japan. J Allergy Clin Immunol Pract 2021;9:494-496.e1, doi:http://dx.doi.org/10.1016/j. jaip.2020.09.060.

Bernal JL, Cummins S, Gasparrini A. Interrupted time series regression for the evaluation of public health interventions: a tutorial. Int $\mathrm{J}$ Epidemiol 2017;46:348-55, doi:http://dx.doi.org/10.1093/ije/dyw098.

Chan KPF, Ma TF, Kwok WC, Leung JKC, Chiang KY, Ho JCM, et al. Significant reduction in hospital admissions for acute exacerbation of chronic obstructive pulmonary disease in Hong Kong during coronavirus disease 2019 pandemic. Respir Med 2020;171:106085, doi:http://dx.doi.org/ 10.1016/j.rmed.2020.106085.

de Souza Luna LK, Perosa DAH, Conte DD, Carvalho JMA, Alves VRG, Cruz JS, et al. Different patterns of influenza A and B detected during early stages of COVID-19 in a university hospital in São Paulo, Brazil. J Infect 2020;81:e104-5, doi:http:/| dx.doi.org/10.1016/j.jinf.2020.05.036.

Hamada H, Sekimoto M, Imanaka Y. Effects of the per diem prospective payment system with DRG-like grouping system (DPC/PDPS) on resource usage and healthcare quality in Japan. Health Policy 2012;107:194-201, doi:http://dx.doi. org/10.1016/j.healthpol.2012.01.002.

Hammad TA Parikh M, Tashtish N, Lowry CM, Gorbey D, Forouzandeh F, et al. Impact of COVID-19 pandemic on ST-elevation myocardial infarction in a non-COVID19 epicenter. Catheter Cardiovasc Interv 2021;97(2):208-14, doi:http://dx.doi. org/10.1002/ccd.28997.

Janssens J-P. Pneumonia in the elderly (geriatric) population. Curr Opin Pulm Med 2005;11:226-30, doi:http://dx.doi.org/10.1097/01.mcp.0000158254.90483.1f.

Jones N. How COVID-19 is changing the cold and flu season. Nature 2020;588:38890, doi:http://dx.doi.org/10.1038/d41586-020-03519-3.

Kishimoto K, Bun S, Shin J, Takada D, Morishita T, Kunisawa S, et al. Early impact of school closure and social distancing for COVID-19 on the number of inpatients with childhood non-COVID-19 acute infections in Japan. Eur J Pediatr 2021;1-8, doi:http://dx.doi.org/10.1007/s00431-021-04043-w.

Komiya K, Yamasue M, Takahashi O, Hiramatsu K, Kadota J-I, Kato S. The COVID-19 pandemic and the true incidence of tuberculosis in Japan. J Infect 2020;81(3): e24-25, doi:http://dx.doi.org/10.1016/j.jinf.2020.07.004.

Lazzerini M, Barbi E, Apicella A, Marchetti F, Cardinale F, Trobia G. Delayed access or provision of care in Italy resulting from fear of COVID-19. Lancet Child Adolesc Health 2020;4(5):e10-11, doi:http://dx.doi.org/10.1016/S2352-4642(20)30108-5.

Mandell LA, Niederman MS. Aspiration pneumonia. N Engl J Med 2019;380:651-63. doi:http://dx.doi.org/10.1056/NEJMra1714562.

Metlay JP, Waterer GW, Long AC, Anzueto A, Brozek J, Crothers K, et al. Diagnosis and treatment of adults with community-acquired pneumonia. An Official Clinical Practice Guideline of the American Thoracic Society and Infectious Diseases Society of America. Am J Respir Crit Care Med 2019;200:e45-67, doi:http://dx. doi.org/10.1164/rccm.201908-1581ST.

Ministry of Health, Labour and Welfare. Guidelines for "A Survey for Assessing the Effects of Introduc- ing DPC" in fiscal year 2020. 2020. https://www01.prrism. com/dpc/2020/top.html. 
Ministry of Health, Labour and Welfare. Distribution of medical supplies and emergency response by medical institutions. 2018. https://www.mhlw.go.jp/ toukei/saikin/hw/iryosd/m18/is1802.html.

Ministry of Health, Labour and Welfare. Reports of a survey, "Discharged Patients Survey," for assessing the effects of introducing DPC. 2018. https://www.mhlw. go.jp/stf/shingi2/0000196043_00003.html.

Murcia J, Llorens P, Sánchez-Payá J, Reus S, Boix V, Merino E, et al. Functional status determined by Barthel Index predicts community acquired pneumonia mortality in general population. J Infect 2010;61:458-64, doi:http://dx.doi. org/10.1016/j.jinf.2010.08.006.

Nguyen MTN, Saito N, Wagatsuma Y. The effect of comorbidities for the prognosis of community-acquired pneumonia: an epidemiologic study using a hospital surveillance in Japan. BMC Res Notes 2019;12:817, doi:http://dx.doi.org/ 10.1186/s13104-019-4848-1.

Prasso JE, Deng JC. Postviral complications: bacterial pneumonia. Clin Chest Med 2017;38:127-38, doi:http://dx.doi.org/10.1016/j.ccm.2016.11.006.

Prime Minister of Japan and His Cabinet. Declaration of a state of emergency in response to the novel coronavirus disease. 2020. https://japan.kantei.go.jp/ ongoingtopics/_00018.html.

Sakamoto $\mathrm{H}$, Ishikane M, Ueda P. Seasonal influenza activity during the SARS-CoV-2 outbreak in Japan. JAMA 2020;323:1969-71, doi:http://dx.doi.org/10.1001/ jama.2020.6173.

Shimizu K, Wharton G, Sakamoto H, Mossialos E. Resurgence of covid-19 in Japan. BMJ 2020;370:m3221, doi:http://dx.doi.org/10.1136/bmj.m3221.

Shindo Y, Sato S, Maruyama E, Ohashi T, Ogawa M, Imaizumi K, et al. Comparison of severity scoring systems A-DROP and CURB-65 for community-acquired pneumonia. Respirology 2008;13:731-5, doi:http://dx.doi.org/10.1111/j.14401843.2008.01329.x.

Takada D, Kunisawa S, Matsubara T, Fushimi K, Yanagita M, Imanaka Y. Developing and validating a multivariable prediction model for in-hospital mortality of pneumonia with advanced chronic kidney disease patients: a retrospective analysis using a nationwide database in Japan. Clin Exp Nephrol 2020;24:71524, doi:http://dx.doi.org/10.1007/s10157-020-01887-8.

Weinberger DM, Simonsen L, Jordan R, Steiner C, Miller M, Viboud C. Impact of the 2009 influenza pandemic on pneumococcal pneumonia hospitalizations in the United States. J Infect Dis 2012;205:458-65, doi:http://dx.doi.org/10.1093/ infdis/jir749.

Wu D, Lu J, Cao L, Ma X, Liu Q, Liu Y, et al. Positive effects of COVID-19 control measures on pneumonia prevention. Int J Infect Dis 2020;96:548-9, doi:http:// dx.doi.org/10.1016/j.ijid.2020.05.069.

Yamamoto T, Komiya K, Fujita N, Okabe E, Hiramatsu K, Kadota J-I. COVID-19 pandemic and the incidence of community-acquired pneumonia in elderly people. Respir Investig 2020;58(6):435-6, doi:http://dx.doi.org/ 10.1016/j.resinv.2020.09.001.

Zhou W, Wang A, Wang X, Cheke RA, Xiao Y, Tang S. Impact of hospital bed shortages on the containment of COVID-19 in Wuhan. Int J Environ Res Public Health 2020;17:, doi:http://dx.doi.org/10.3390/ijerph17228560.

Zhu N, Zhang D, Wang W, Li X, Yang B, Song J, et al. A novel coronavirus from patients with pneumonia in China, 2019. N Engl J Med 2020;382:727-33, doi:http://dx. doi.org/10.1056/NEJMoa2001017. 